\title{
Avaliação de impactos da Lei de Informática: uma análise da política industrial e de incentivo à inovação no setor de TICs brasileiro*
}

\author{
Sergio Salles Filho \\ Faculdade de Ciências Aplicadas da Unicamp, Departamento de Política Científica e Tecnológica (DPCT), Grupo \\ de Estudo sobre Organização da Pesquisa e da Inovação (Geopi/DPCT/Unicamp), Brasil \\ Giancarlo Stefanuto \\ Grupo de Estudo sobre Organização da Pesquisa e da Inovação (Geopi/DPCT/Unicamp), Brasil \\ Carolina Mattos \\ Grupo de Estudo sobre Organização da Pesquisa e da Inovação (Geopi/DPCT/Unicamp), Brasil

\section{Camila Zeitoum} \\ Grupo de Estudo sobre Organização da Pesquisa e da Inovação (Geopi/DPCT/Unicamp), Brasil \\ Fabio Rocha Campos \\ Grupo de Estudo sobre Organização da Pesquisa e da Inovação (Geopi/DPCT/Unicamp), Brasil
}

\section{RESUMO}

Este trabalho objetivou identificar em que medida a Lei de Informática (LI) levou ao aumento da densidade produtiva e tecnológica da indústria de tecnologias da informação e comunicação (TICs) no Brasil e à ampliação de sua participação no mercado internacional. Foram aplicados questionários eletrônicos em empresas usuárias da LI e Instituições de Ciência e Tecnologia (ICTs). Concluiu-se que a LI estimulou a expansão do mercado de TICs no Brasil por meio

* Os autores agradecem aos pareceristas anônimos da RBI pelos comentários e sugestões. 
da produção local, mas com limitada adição de valor. As empresas ampliaram sua capacidade de inovação, porém não houve aumento significativo da participação do Brasil nas exportações de bens eletrônicos. Para ampliar os impactos da LI, propóe-se: aproveitamento dos setores de alta competitividade do país; foco no mercado global e exportações; identificação e estímulo do núcleo estratégico das empresas beneficiárias; e implantação de um sistema de avaliação continuada, composto por um sistema de indicadores para medição da densidade produtiva e tecnológica da indústria.

PALAVRAS-CHAVE | Tecnologias da informação e comunicação; Incentivo fiscal; pesquisa e desenvolvimento; Avaliação de impactos; Lei de Informática .

Códigos JEL | O15; L12.

\section{Impact assessment of ICT Policy: analysis of the industrial and incentive policy for innovation in the Brazilian ICT sector}

\section{ABSTRACT}

The objective of this research was to identify to which extent the ICT Law lead to a raise of the productive and technological density of the ICT industry in Brasil and the raise of its participation in the international ICT market. Two kinds of online questionnaires were applied: to the companies which used the Law and to the Science and Technology Institutions (STI) - universities and research institutes. $70 \%$ of the companies answered the questionnaire and $60 \%$ in the case of the STI. The study concludes that the Law stimulated market expansion of the Brazilian ICT sector through local production, but with limited value aggregation. The companies raised their innovation capacity, however with irrelevant participation on the country's electronic products exports. Adjustments of the actual mechanisms of the IL to raise its effectiveness are proposed and also new mechanisms to build up the most innovative companies.

KEYWORDS | Information and communication technologies; Fiscal incentives; Public policies; Research and development; Added value.

JEL-Codes | O15; L12. 


\section{Introdução}

A Lei de Informática (LI) é um instrumento de política industrial criado no Brasil, no início da década de 1990, para ajudar os fabricantes de hardware nacionais a enfrentar os desafios impostos pelo fim da reserva de mercado que se avizinhava, assim como incentivar a realização de atividades de Pesquisa e Desenvolvimento (P\&D) no setor de Tecnologias da Informação e Comunicação (TICs) no país. O objetivo inicial da Lei era incentivar a fabricação local de produtos de automação e tecnologias da informação no país e, em decorrência dessa produção com incentivo fiscal, as empresas deveriam investir em atividades de P\&D.

Para usufruir desses benefícios fiscais, as empresas tinham que investir ao menos 5\% do seu faturamento (excluindo software e serviços profissionais) em atividades de $P \& D$, sendo que até $3 \%$ poderiam ser em atividades internas e $2 \%$ deveriam ser com os projetos comuns com universidades, institutos de pesquisa ou em programas governamentais.

Este formato da legislação brasileira vigorou de 1992 até 2000, quando foi modificado pela Lei $\mathrm{n}^{\circ} 10.176 / 01$, que manteve os mesmos princípios e instrumentos básicos, mas modificou os percentuais aplicados às atividades internas (2,7\%) e externas $(2,3 \%)$, sendo que, nestas últimas, foram estabelecidos percentuais de aplicação obrigatória nas Regiōes Norte, Nordeste e Centro-Oeste do país. Posteriormente, a Lei no 11.077/2004 introduziu modificações, basicamente estendendo os prazos dos benefícios até 2019, porém com uma redução gradativa das isenções fiscais. Além disso, no início da Lei, a base de cálculo referia-se ao faturamento bruto das empresas beneficiárias no mercado interno decorrente da comercialização de bens e serviços de informática, deduzidos os tributos correspondentes a tais comercializações. Em 2001, a base passou a ser o faturamento bruto dessas empresas no mercado interno, decorrente da comercialização de bens e serviços de informática, deduzidos os tributos correspondentes a tais comercializaçôes, bem como o valor das aquisições de produtos incentivados. Já em 2004, a base passou a se referir ao faturamento bruto das beneficiárias no mercado interno, decorrente da comercialização de bens e serviços de informática, incentivados pela Lei. Essas mudanças, como será apresentado adiante, foram significativas no que diz respeito à redução relativa dos investimentos em $\mathrm{P} \& \mathrm{D}$ ao longo do período.

Embora fosse o principal instrumento da Política de Informática vigente nas décadas de 1990 e 2000, ainda não havia uma visão precisa da real contribuição desta Lei para o aumento do nível de competitividade do setor de TICs brasileiro. Assim, 
o Ministério da Ciência e Tecnologia do Brasil contratou, em julho de 2009, um estudo de avaliação de impactos da Lei de Informática, junto ao Centro de Gestão de Estudos Estratégicos (CGEE), em parceria com o Grupo de Estudos sobre Organização da Pesquisa e da Inovação (Geopi), do Departamento de Política Científica e Tecnológica do Instituto de Geociências da Unicamp. O estudo teve duração de 18 meses. O presente documento traz um resumo dos resultados dessa avaliação, além de indicar proposições de ações para ampliação dos impactos esperados. ${ }^{1}$

Inicialmente apresenta-se, de maneira sucinta, um panorama global da indústria de TICs e o posicionamento do Brasil frente a alguns dos principais indicadores que caracterizam esta indústria. A seguir, é feito um relato acerca da metodologia utilizada para o desenvolvimento do trabalho. São resumidos também os principais resultados e impactos da Lei de Informática nas empresas incentivadas e nas Instituições de Ciência e Tecnologia (ICTs) com as quais as empresas realizaram P\&D em parceria, outra obrigação da Lei. Por fim, são apresentadas as principais conclusões e propostas para ampliar os impactos da Lei de Informática.

\section{O Brasil no cenário internacional da indústria de TICs}

A indústria eletrônica ${ }^{2}$ global vem se deslocando e se concentrando no Leste Asiático, especialmente na China, Hong Kong, Coreia do Sul, Cingapura e Taiwan. O Brasil participa da produção de eletrônicos, mas com montantes muito inferiores aos de seus concorrentes. Enquanto só a China produzia US\$ 413 bilhōes em 2008, o Brasil competia com US\$37 bilhões e os EUA, atualmente segundo maior produtor, participavam com US\$ 282 bilhões. Do montante de produção dos dez maiores produtores de eletrônicos do mundo em 2008 (US\$ 1,3 trilhão), China, Coreia do

1 Agradecemos aos pareceristas pelas importantes críticas e sugestões.

2 A definição de equipamentos eletrônicos e tecnologias da informação e comunicação, assim como produtos, serviços e conteúdos de TICs, vem evoluindo desde 1998 quando foi publicada a primeira definição oficial de setor de TICS baseada na International Standard Industrial Classification of all Economic Activities rev. 3 - ISIC. Desde então os órgãos oficiais de classificação têm adequado as métricas às rápidas mudanças tecnológicas e de mercado. De todo modo, a classificação mais recente (OCDE, 2008a) de produtos de TICs é: "Produtos TIC devem ser prioritariamente destinados a cumprir ou ativar a função de informação, processamento e comunicação por meios eletrônicos, incluindo a transmissão e exibição". Assim, todo produto de TICs funciona por meio eletrônico, mas nem todo eletrônico pode ser considerado uma TIC, embora a convergência digital esteja reduzindo cada vez mais essa fronteira. Assim, hoje, video games, câmeras, televisores, aparelhos de som, equipamentos geradores e transmissores de energia são considerados produtos de TICs, além dos já anteriormente classificados computadores, terminais, equipamentos de telecomunicações, médico-hospitalares, etc. Em breve, eletrodomésticos assim como outros equipamentos também poderão mudar de categoria. A OCDE aponta que uma das maneiras de mudar um produto de categoria está em quanto de seu valor está em relacionado a TICs. Contudo, pressupõe-se que a capacidade de um país produzir componentes eletrônicos pode contribuir para seu posicionamento competitivo na indústria de TICs. 
Sul, Malásia, Cingapura e China Taipei eram responsáveis por, aproximadamente, 52\%. O Brasil respondia por menos de 3\% (OCDE, 2008).

Em relação à exportação, de acordo com dados da $\mathrm{OCDE},{ }^{3}$ o Brasil se manteve, em 2008, na mesma posição que ocupava em 1998: $27^{\circ}$ lugar no ranking de países exportadores de bens de TICs. Nesse período de dez anos, o montante exportado passou de US\$ 1 bilhão/ano para US\$ 2 bilhões/ano. Neste mesmo período a China aumentou suas exportações de bens de TICs de US\$ 26 bilhões/ano para US\$ 379 bilhões/ano, os EUA de US\$ 121 bilhões/ano para US\$ 141 bilhões/ano e Coreia do Sul de US\$ 34 bilhôes/ano para US\$ 114 bilhões/ano.

Entre 1998 e 2007, a China ultrapassou os EUA na exportação de equipamentos de TICs, passando do $8^{\circ}$ para o $1^{\circ}$ lugar (um aumento de dez vezes na produção de bens de TICs), enquanto a Coreia do Sul subiu da $5^{\text {a }}$ para a $3^{a}$ posição. Em relação à participação do setor de TICs no total de bens exportados, China e Coreia do Sul apresentavam, aproximadamente, $1 / 3$ do total de suas exportaçóes relacionadas com este estratégico setor. Já nos EUA e Japão, estas proporções eram, em 2008, de $12 \%$ e $14 \%$, respectivamente, enquanto o Brasil, embora sendo o maior mercado de TICs da América Latina, registrava um percentual de apenas 1\%.

A balança comercial brasileira de bens de TICs vem apresentando significativo aumento do déficit comercial, principalmente para componentes eletrônicos. De acordo com dados da Fundação Centro de Estudos de Comércio Exterior (Funcex), ${ }^{4}$ houve ampliação da importação de componentes de US\$ 6,7 bilhões/ano para US\$ 14,2 bilhões/ano, entre 1998 e 2007 . No segmento de componentes eletrônicos, os maiores exportadores são os EUA (superávit de US\$ 24 bilhões), Japão (superávit de US\$ 22 bilhões), Coreia (déficit US\$ 1 bilhão), Alemanha (déficit de US\$ 3 bilhões) e China, que exporta US\$ 25 bilhões e importa US\$ 131 bilhões, apresentando um déficit de US\$ 106 bilhões em 2008. O México possui um déficit de US\$ 10 bilhões, crescente, pois importa esse insumo para a fabricação de produtos finais, bem semelhante ao Brasil.

Apesar de serem grandes exportadores de componentes eletrônicos, países com alto valor bruto de produção de TICs, como EUA e Alemanha, apresentaram déficits crescentes na balança comercial da manufatura eletrônica em geral. A Coreia, por sua vez, possui valor bruto de produção crescente e saldo positivo na balança comercial. No caso dos Estados Unidos, cujo aumento do déficit é muito maior do que nos demais países, o crescimento das exportações no período não

3 Fonte: <http://stats.oecd.org $>$.

4 Fonte: <http://www.funcexdata.com.br/br/>. 
chegou a 20\%, enquanto as importações ampliaram-se em quase 70\%, entre 1998 e 2008. Os altos valores de importações de bens de TICs da China e Coreia do Sul estão também vinculados ao elevado volume de exportação destes países. No caso da China, o aumento das importaçôes foi de cerca de 95\%, enquanto o das exportações foi superior a 140\%, entre 1998 e 2008. Estas variações se refletiram, evidentemente, no crescimento considerável do market-share mundial do setor de TICs do país, que correspondeu a cerca de 20\% (OCDE, 2008). ${ }^{5}$ Em parte, isso se explica pelas políticas chinesas mais recentes de desenvolvimento econômico que estimularam melhorias qualitativas e quantitativas das exportações do país - dada a ênfase nos avanços tecnológicos na indústria elétrica e eletrônica, além de incentivos fiscais e de outras naturezas, bem como a atração de investimento direto estrangeiro na indústria de transformação.

O aumento das exportações brasileiras de bens de TICs (196\%) foi maior do que o das importaçôes do setor no período (163\%). Porém, os valores de importações do país são consideravelmente maiores do que os de exportação: em 2008, por exemplo, as exportações brasileiras de TICs alcançaram pouco mais de US\$ 3 bilhões, enquanto as importações nesse setor ultrapassaram os US\$ 16 bilhões. Os componentes para informática e telecomunicações, além dos semicondutores, estão entre os principais conjuntos de produtos importados, o que ajuda a explicar o alto valor das importações do país. ${ }^{6}$

\section{Objetivos e métodos}

O estudo teve como objetivo identificar em que medida a Lei de Informática (Lei 8.248/91 e suas alteraçôes) promoveu o aumento da densidade produtiva e tecnológica na indústria brasileira de Tecnologias da Informação e Comunicação, no período de 1998 a 2008. A partir deste macro-objetivo, foram definidos temas e indicadores de análise ${ }^{7}$ para avaliar os impactos da Lei nos seguintes aspectos:

5 Fonte: $<$ http://stats.oecd.org $>$.

6 Fonte: <http://www.funcexdata.com.br/br/>.

7 Os temas de análise foram construídos a partir da aplicação do Método da Decomposição, desenvolvido pelo Geopi (SALLES-FILHO et al., 2011). A lista de temas e indicadores foi então apresentada e validada em um painel de especialistas, que contou 60 participantes de diferentes organizações, tais como empresas beneficiárias (nacionais e multinacionais), Instituições de Ciência e Tecnologia (privadas e públicas), Banco Nacional de Desenvolvimento Econômico e Social (BNDES), Financiadora de Estudos e Projetos (Finep), IBGE, Instituto de Pesquisas Aplicadas (Ipea), Ministério de Ciência, Tecnologia e Inovação (MCTI), Universidade Federal do Rio de Janeiro (UFRJ) e Centro das Indústrias do Estado de São Paulo (Ciesp). 
capacidade de pesquisa; desenvolvimento e inovação (PDI); tecnologias desenvolvidas; formação de parcerias e redes de desenvolvimento tecnológico e de inovação entre setor público e privado; produção científica e acadêmica; criação de cultura de inovação; descentralização regional do desenvolvimento científico-tecnológico; e ampliação da cadeia produtiva.

Os temas e indicadores definidos orientaram a coleta de dados que se deu a partir das seguintes fontes:

- base de dados da Secretaria para Política de Informática do Ministério de Ciência e Tecnologia (Sepin/MCT) - Relatórios Demonstrativos de Acompanhamento das Atividades de P\&D das Empresas Beneficiárias. Parte dos macroindicadores (investimentos em P\&D, RH de nível superior, etc.) foi coletada a partir da base de dados consolidada da Sepin;

- tabulaçóes especiais geradas pelo Instituto Brasileiro de Geografia e Estatística (IBGE) - foram elaboradas tabulações especiais a partir da lista de Cadastro Nacional de Pessoa Jurídica (CNPJs) das empresas beneficiárias da Lei. As tabulações foram extrações da Pesquisa Industrial Anual - PIA e Pesquisa de Inovação Tecnológica - Pintec; ${ }^{8}$

- bases públicas de dados estatísticos - foram coletados dados nas bases de dados da Organisation for Economic Co-operation and Development (OCDE/Stats), United Nations (ONU/Comtrade), Organização Mundial do Comércio (OMC), Secretaria de Comércio Exterior do Brasil (Secex), IBGE, Funcex, International Labour Organization (ILO), entre outras, para caracterizar a participação do Brasil no mercado internacional de TICs;

- dados fornecidos pelas empresas e Instituições de Ciência e Tecnologia (ICTs) por meio de questionário eletrônico. De um universo de 285 empresas beneficiárias, 196 responderam aos questionários de avaliação (69\% do total), e de um universo de 101 ICTs, 58 responderam à pesquisa $(57 \%)$;

- $\quad$ entrevistas presenciais - foram realizadas, aproximadamente, 30 entrevistas em empresas e ICTs com diversos perfis ao longo da avaliação, tanto para testar e validar os questionários de avaliação quanto para que houvesse maior compreensão acerca dos resultados que mais se destacaram nas respostas dadas aos questionários.

8 Do universo de 285 empresas beneficiárias, 223 foram localizadas nas bases da PIA 2007 e 195 na Pintec 2005. 
Com relação às empresas participantes da avaliação, foram convidadas todas aquelas que usufruíram ao menos uma vez ou continuam usufruindo os benefícios da Lei de Informática, entre 1998 e 2008. A amostra de empresas que responderam ao questionário eletrônico caracteriza-se por perfis diferenciados em termos de porte, localização geográfica e origem de capital, conforme se verifica na Tabela 1.

TABELA 1

Distribuição das empresas que responderam ao questionário de avaliação, segundo características

Brasil-2010

\begin{tabular}{lcc}
\hline Características das empresas & N. Abs. & $\%$ \\
\hline Porte & 21 & 10,7 \\
Grande & 23 & 11,7 \\
Média-grande & 62 & 31,6 \\
Média & 75 & 38,3 \\
Pequena & 15 & 7,7 \\
Microempresa & & \\
Região & 5 & 2,6 \\
Centro-Oeste & 21 & 10,7 \\
Nordeste & 58 & 29,9 \\
Sul & 112 & 57,1 \\
Sudeste & & 14,8 \\
Origem do capital & 29 & \\
Estrangeira & & \\
\hline
\end{tabular}

Fonte: CGEE (2011).

Para a configuração da amostra das Instituições de Ciência e Tecnologia (ICTs), optou-se por um recorte que possibilitou melhores interpretações das informações coletadas. Da amostra inicial de 58 ICTs, verificou-se alta concentração dos recursos de convênios em poucas instituições. Foram então selecionadas 15 ICTs para comporem a amostra, cujos dados foram analisados na presente avaliação, e que estão entre as 20 instituiçóes que concentram a maior parte dos recursos de convênio (84\% de toda aplicação em P\&D). 
TABELA 2

Distribuição das ICTs que responderam ao questionário de avaliação, segundo características das instituições

\begin{tabular}{lcc}
\hline Características das instituições & N. Abs. & \% \\
\hline Natureza & 3 & 17,0 \\
Privada de ensino & 8 & 56,0 \\
Privada de pesquisa & 3 & 22,0 \\
Pública de ensino & 1 & 5,0 \\
Pública de pesquisa & & \\
Região & 1 & 7,0 \\
Centro-Oeste & 5 & 33,0 \\
Nordeste & 2 & 13,0 \\
Sul & 7 & 47,0 \\
Sudeste & $\mathbf{1 5}$ & $\mathbf{1 0 0 , 0}$ \\
Total & & \\
\hline
\end{tabular}

Fonte: CGEE (2011).

\section{Resultados da Lei de Informática}

\subsection{Faturamento das empresas beneficiárias}

Como pode ser observado no Gráfico 1, o faturamento das empresas incentivadas quadruplicou no período 1998-2008, passando de pouco mais de R \$ 10 bilhōes para aproximadamente R $\$ 50$ bilhôes. Em 2008, metade do faturamento total correspondia a produtos incentivados pela Lei de Informática. De acordo com dados do IBGE, o crescimento do faturamento das beneficiárias foi 1,7 vez maior do que o das não beneficiárias da indústria. A PIA/IBGE indicava que o valor bruto da produção industrial na manufatura de TICs do país somava, em 2007, $\mathrm{R} \$ 90$ bilhōes ao todo. Assim, o faturamento das empresas incentivadas respondia por cerca de $50 \%$ daquele da indústria nacional de TICs e os bens incentivados correspondiam a $25 \%$. 


\section{GRÁFICO 1}

Faturamento das empresas beneficiadas pela Lei de Informática: total e com produtos incentivados

Brasil - 1997-2009

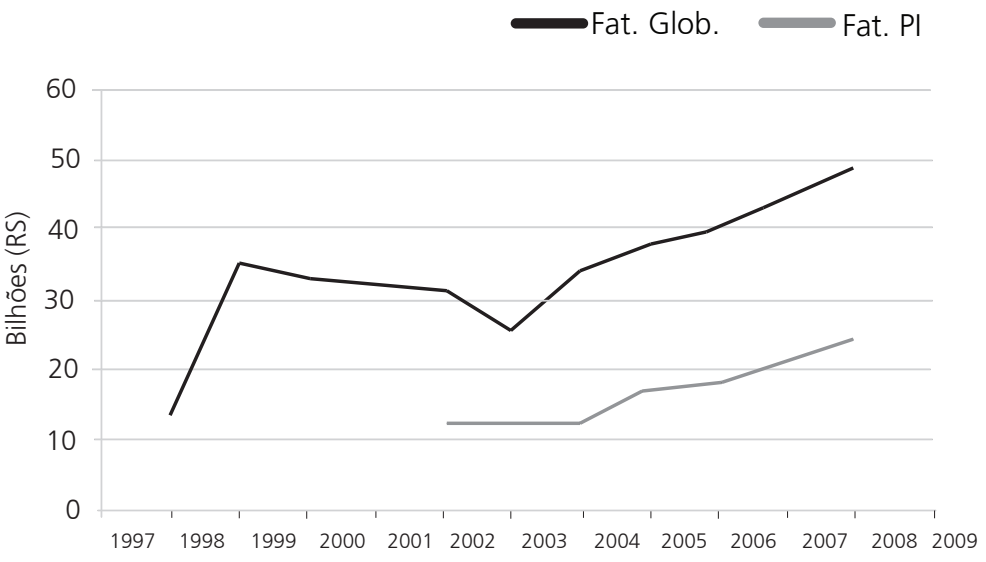

Fonte: CGEE (2011).

$\mathrm{O}$ investimento total em P\&D das empresas beneficiárias cresceu 30\% de 2003 a 2008, passando de R\$ 670 milhões/ano para R\$ 879 milhões/ano, sendo que o investimento realizado além da obrigação legal, em média, foi de $40 \%$ do total investido em P\&D (Base Sepin/MCT). Contudo, em função de mudanças na legislação (em 2002 e 2004), que reduziram a base de cálculo para investimento em $\mathrm{P} \& \mathrm{D}$, as obrigações dos investimentos em $\mathrm{P} \& \mathrm{D}$, a partir de então, foram inferiores aos patamares de 1998 a 2001 (por volta de R\$ 1 bilhão/ano), como pode ser observado no Gráfico 2.

Esta redução das obrigações também é percebida quando se compara o investimento em $\mathrm{P} \& \mathrm{D}$ realizado vis-à-vis a renúncia fiscal auferida no mesmo período. Ou seja, a relação entre investimento em $\mathrm{P} \& \mathrm{D}$ e renúncia fiscal decresceu significativamente entre 2002 e 2008: de 0,62 para 0,26. Ainda que se possa dizer que esta relação iniciou-se em um patamar elevado, o decréscimo foi substantivo, revelando um enfoque mais voltado para a produção de bens finais do que para o desenvolvimento de novos produtos e processos.

Em que pese esta redução, as obrigações decorrentes da Lei fazem com que as empresas incentivadas invistam em $\mathrm{P} \& \mathrm{D}$ bem mais do que as não incentivadas. De acordo com os dados selecionados da Pintec 2005, os investimentos em P\&D das empresas beneficiárias foram três vezes maiores do que a média do restante da indústria de TICs brasileira, com pequenas e médias empresas ampliando em 
$43 \%$ seus investimentos e as grandes empresas em 17\%. Observa-se que, mesmo representando apenas 5\% do universo da indústria brasileira de TICs, em 2007, as usuárias da Lei investiram quase $60 \%$ de todo o investimento na indústria de TICs.

\section{GRÁFICO 2}

Investimentos em P\&D das empresas beneficiárias: obrigações decorrentes do incentivo da Lei de Informática e aplicações totais Brasil - 1997-2009

Aplicação em P\&D $\quad$ Obrigação em P\&D

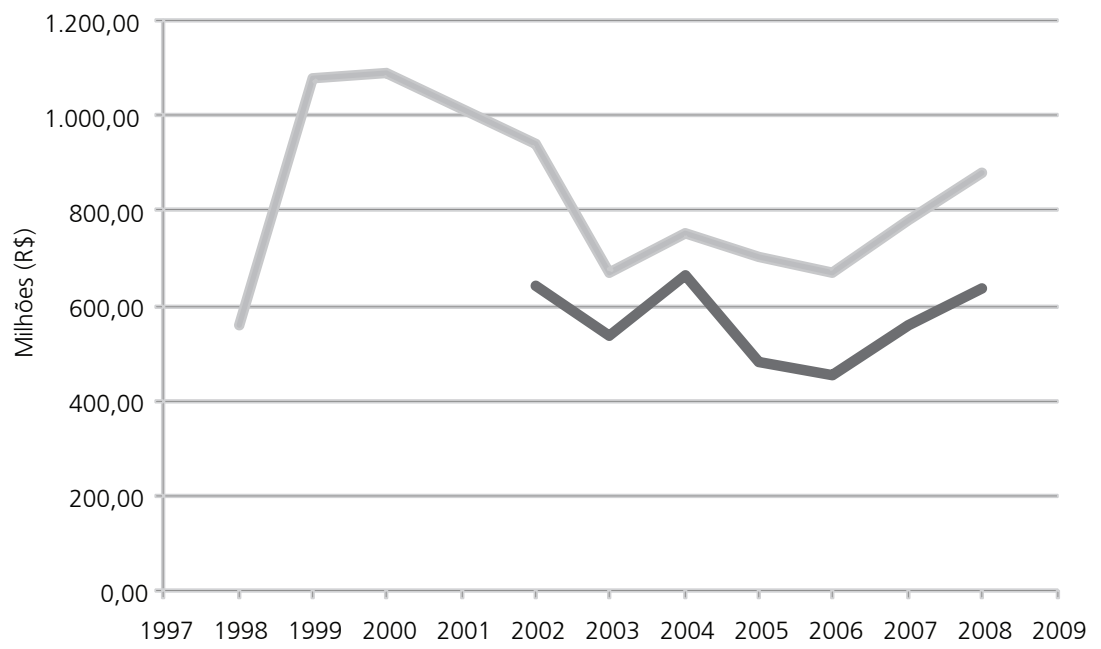

Fonte: CGEE (2011).

Percebe-se, assim, que as empresas beneficiárias da Lei de Informática vêm aumentando seu investimento em $\mathrm{P} \& \mathrm{D}$ para além das obrigaçôes legais e em níveis superiores aos da média da indústria. Entretanto, dadas as mudanças no marco legal, os valores hoje são inferiores aos praticados nos primeiros anos da Lei.

Além disso, a maioria das empresas transnacionais desta indústria presentes no Brasil é usuária da Lei e os maiores investimentos em P\&D decorrem delas. Das 20 empresas com maior obrigação de investimento de P\&D, no período de 2006 a 2009, em média, quatro são nacionais e as demais são estrangeiras de grande porte. Do grupo de empresas com investimento superior a R \$ 10 milhões, nos anos mais recentes (2008 e 2009), apenas uma é nacional. As empresas de computadores e celulares encontram-se entre as beneficiárias que mais investem. 


\subsection{Qualificação de recursos humanos (RH)}

A análise da base da Sepin mostra que, entre 1998 e 2008, as empresas beneficiárias da LI triplicaram a força de trabalho total. Apesar deste crescimento, a participação de pós-graduados no total de $\mathrm{RH}$ alocado em P\&D caiu pela metade em termos relativos, neste mesmo período (de 2,4\% para 1,2\%). As empresas beneficiárias não apresentaram expansão relevante na contratação de pessoal de nível superior. A proporção de $\mathrm{RH}$ com este grau de escolaridade em relação ao total de pessoal ocupado em P\&D manteve-se em cerca de 5\% ao longo do período estudado. Ou seja, a evolução de RH de nível superior foi vegetativa, muito embora em termos absolutos tenha sido significativa (300\% de aumento).

$\mathrm{O}$ crescimento de RH em P\&D decorre basicamente da ação das grandes empresas das Regiōes Sul e Sudeste (Gráfico 3) e a participação de RH com nível superior em $\mathrm{P} \& \mathrm{D}$ no total de pessoal alocado em P\&D estabilizou-se em $70 \%$ nos três últimos anos, para as grandes empresas. No Sul, o percentual de RH em P\&D tem sido maior do que nas demais regiōes.

\section{GRÁFICO 3}

Participação de RH com nível superior no total de RH em P\&D, por porte das empresas

Brasil - 2002-2008

$$
\begin{aligned}
& \text { [ } 2002 \text { - } 2003 \text { a } 2004 \\
& 2006-2007-2008
\end{aligned}
$$

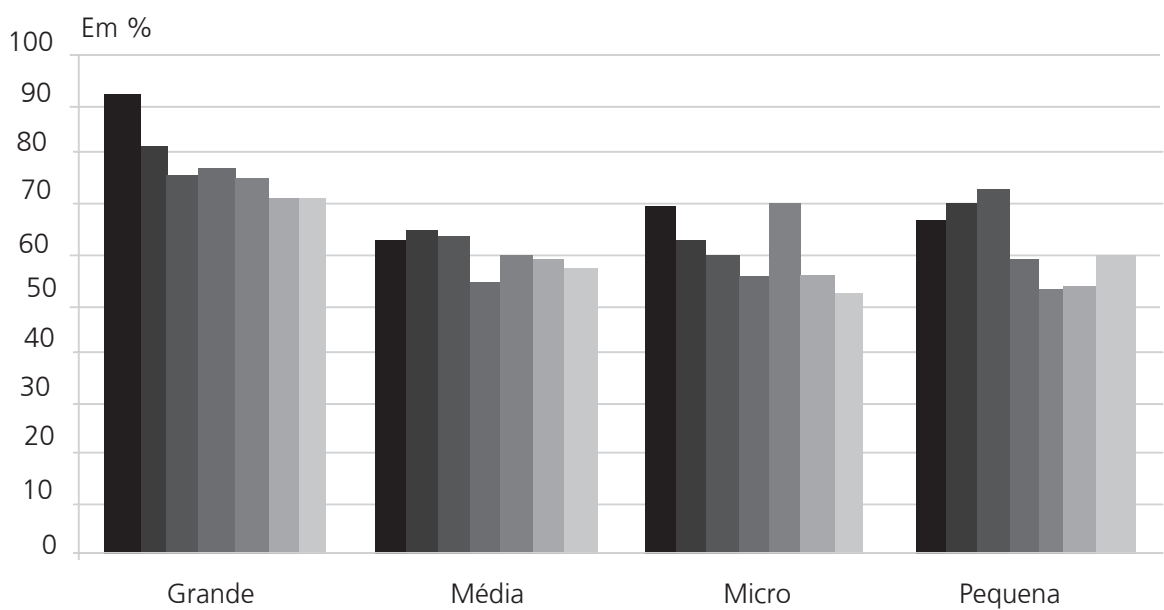

Fonte: CGEE (2011) 


\section{3. $P \& D$ e inovação}

Além da pequena e decrescente participação de pós-graduados no total de $\mathrm{RH}$ em $\mathrm{P} \& \mathrm{D}$, outro aspecto que reforça o foco reduzido em pesquisa é a baixa ocorrência de publicações: apenas $23 \%$ das empresas publicaram, sendo que uma grande empresa concentrou $90 \%$ das publicações.

Entretanto, observou-se, nas diferentes fontes de dados obtidas, que as empresas beneficiárias ampliaram sua capacidade de inovação: $96 \%$ responderam que realizaram alguma inovação, sendo que $19 \%$ das grandes empresas, $10 \%$ das pequenas e $12 \%$ das médias empresas apresentaram inovações consideradas novas para o mundo, como pode ser observado no Gráfico 4.

\section{GRÁFICO 4}

Realização de inovação pelas empresas beneficiárias, por porte, localização geográfica e segmento de atuação das empresas, segundo alcance $(n=189)$ Brasil - 2010

@ Para a empresa $\quad$ Para o país $\quad$ Para o mundo

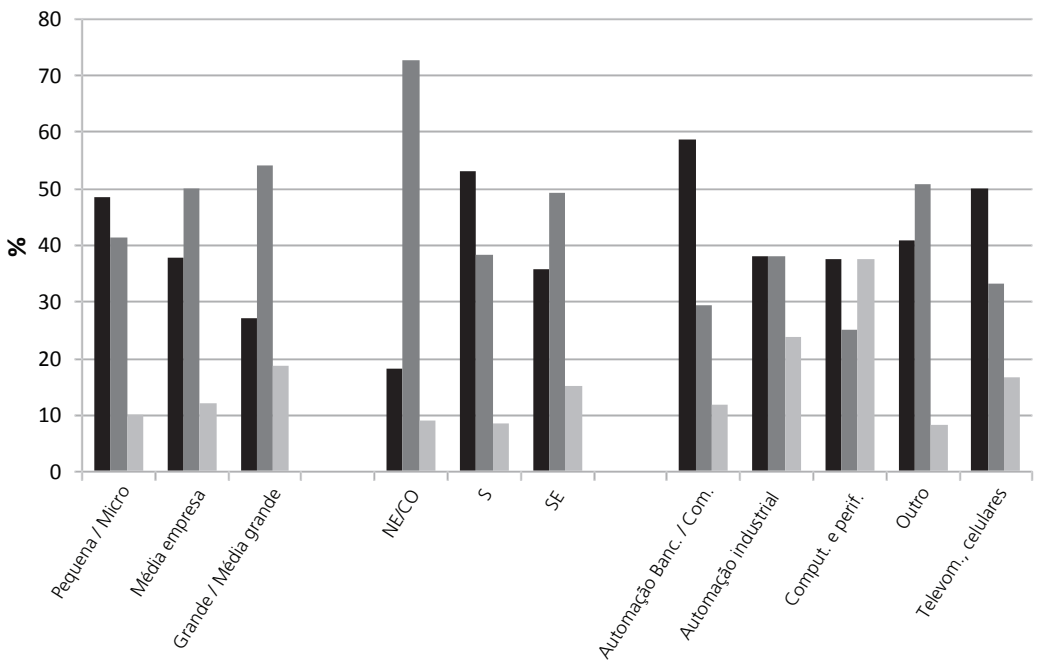

Fonte: CGEE (2011).

Segundo dados do IBGE, as empresas usuárias da Lei inovaram duas vezes mais do que as demais empresas da indústria. Aproximadamente $35 \%$ das beneficiárias da Lei obtiveram inovações a partir da $\mathrm{P} \& \mathrm{D}$ gerada externamente à organização, enquanto para o restante da indústria esta taxa foi de $17 \%$.

Quanto aos Direitos de Propriedade Intelectual (DPI), outro indicador da atividade inovativa, observa-se aumento em quase todos os instrumentos de direito 
de propriedade, com destaque para marcas, desenho industrial e patentes (Tabela 3). Neste crescimento, há uma maior influência da LI em marcas e desenho industrial (40\% e $30 \%$, respectivamente).

Foi também observado ampliação significativa do depósito de patentes (de 13 para 47) no exterior por empresas nacionais, embora em termos absolutos este número ainda seja pouco expressivo. Além disso, as empresas nacionais responderam por um percentual significativo do total de patentes no Brasil (65\%) e no exterior (40\%).

Houve também crescimento da relação benefício/custo do investimento de $\mathrm{P} \& \mathrm{D}^{9}$ - de R $\$ 7$ para $\mathrm{R} \$ 9$ por real investido -, tendo a Lei sido responsável por cerca de 60\% deste aumento. Ou seja, as empresas estão tornando seu investimento em P\&D cada vez mais eficaz (com variaçôes segundo porte e tipo de segmento de mercado das empresas).

TABELA 3

Número de empresas beneficiárias com registros no Brasil e no exterior, segundo instrumentos de direito de propriedade intelectual

Brasil - 2010

\begin{tabular}{|c|c|c|c|c|c|c|}
\hline \multirow{2}{*}{$\begin{array}{l}\text { Instrumentos } \\
\text { de direito de } \\
\text { propriedade } \\
\text { intelectual }\end{array}$} & \multicolumn{6}{|c|}{ Número de registros } \\
\hline & $\begin{array}{l}\text { Empresas } \\
\text { com reg. } \\
\text { no Brasil }\end{array}$ & $\begin{array}{l}\text { Brasil } \\
\text { antes }\end{array}$ & $\begin{array}{l}\text { Brasil } \\
\text { atual }\end{array}$ & $\begin{array}{l}\text { Empresas } \\
\text { com } \\
\text { reg. no } \\
\text { exterior }\end{array}$ & $\begin{array}{l}\text { Exterior } \\
\text { antes }\end{array}$ & $\begin{array}{l}\text { Exterior } \\
\text { atual }\end{array}$ \\
\hline Desenho industrial & 14 & 21 & 89 & 3 & 5 & 15 \\
\hline Marca & 27 & 132 & 526 & 6 & 15 & 171 \\
\hline Modelo de utilidade & 9 & 33 & 56 & 3 & 5 & 9 \\
\hline Patentes & 26 & 74 & 202 & 7 & 13 & 78 \\
\hline Registro de software & 7 & 9 & 30 & 1 & 0 & 2 \\
\hline Segredo industrial & 9 & 50 & 71 & 2 & 2 & 4 \\
\hline $\begin{array}{l}\text { Topografia de circuito } \\
\text { impresso }\end{array}$ & 0 & 0 & 0 & 0 & 0 & 0 \\
\hline Total & & 319 & 974 & & 40 & 279 \\
\hline
\end{tabular}

Fonte: CGEE (2011).

Em coerência com os resultados anteriores, percebeu-se que, no período de 1998 a 2008, ocorreu ampliação da participação de laboratórios de desenvolvimento de empresas multinacionais no total de laboratórios existentes: de 33\% para $67 \%$.

9 A relação benefício/custo de investimento em P\&D é a relação entre o faturamento gerado a partir de cada real investido em P\&D. Esta relação evidencia o amadurecimento organizacional no uso dos recursos para investimento em P\&D para a consecução de resultados (aumento do faturamento). 
Esse fenômeno foi acompanhado por uma mudança no perfil dos investimentos das empresas estrangeiras, direcionados majoritariamente no desenvolvimento experimental e não na pesquisa.

\subsection{Competências adquiridas}

As competências que mais se desenvolveram a partir da influência da Lei foram para adequação ao mercado e adequação aos mecanismos de gestão da Lei. As competências menos desenvolvidas têm perfis variados, mas destaca-se a pequena importância da pesquisa aplicada.

\section{GRÁFICO 5}

Competências desenvolvidas nas empresas beneficiárias, por porte e segmento de atuação

Brasil - 1998-2008

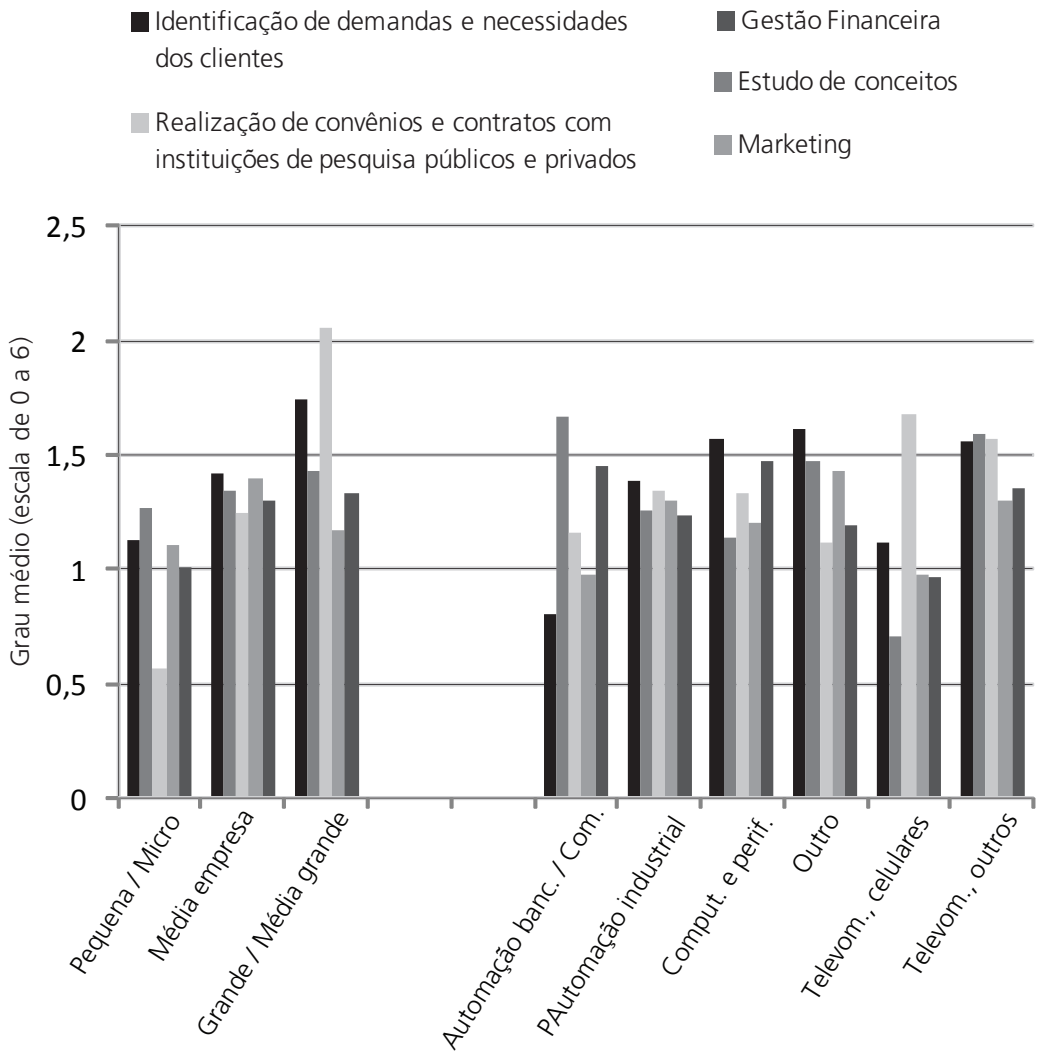

Fonte: CGEE (2011). 
No Gráfico 5 observa-se que as competências que mais sobressaem, tanto na distribuição por porte como por segmento de atuação, são a de identificação de demandas e necessidades de clientes e a de estudo de conceitos. No eixo vertical do Gráfico está o grau médio (escala de 0 a 6) de desenvolvimento das competências.

Analisando-se as competências obtidas, relatadas pelas empresas, percebe-se que, apesar de o espírito da Lei direcionar-se para a geração de tecnologia e inovações, o impacto na geração de competências tecnológicas é restrito. Ou seja, as empresas não indicaram a formação de uma base de conhecimentos e capacidades tecnológicas, não obstante a importância das competências relativas ao entendimento do mercado e as competências organizacionais para amadurecimento empresarial.

\subsection{Adição de valor nas cadeias produtivas}

Para 86\% das empresas, a principal motivação para utilizar a Lei de Informática foi a redução de custos de produção. Tendo foco na fabricação, a Lei não estimulou a entrada das empresas no fornecimento de serviços e em segmentos de hardware de maior valor agregado. A Lei viabiliza a atividade produtiva no país, mas é insuficiente para o desenvolvimento tecnológico e para ampliar a agregação de valor. Um dos aspectos que espelham esta limitada agregação de valor é a relação entre a importação de insumos e o faturamento com produtos incentivados. Esta relação cresceu de 27\% para 58\%, entre 2005 e 2008 (Gráfico 6), com destaque para

\section{GRÁFICO 6}

Relação entre importação de insumos e faturamento com produtos incentivados Brasil - 2001-2009

- Impot/ FPI

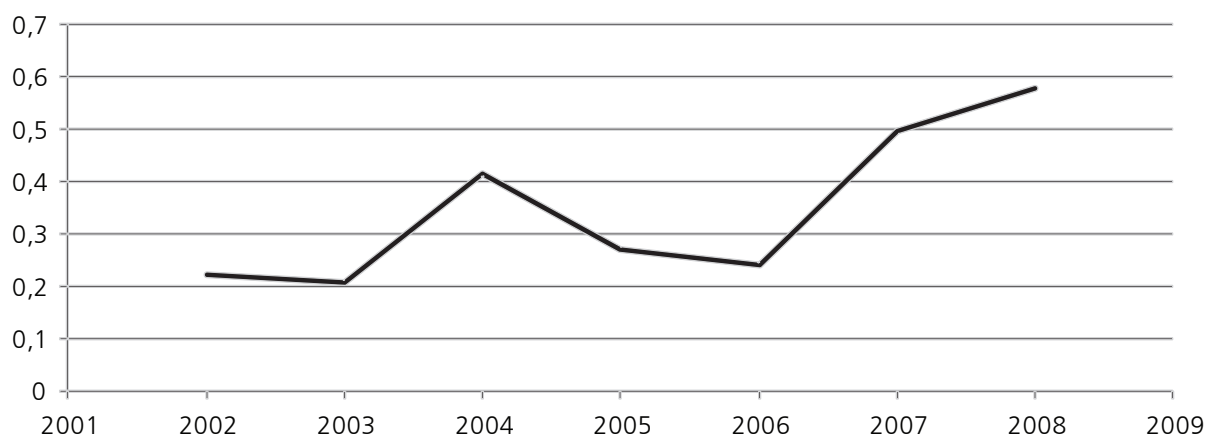

Fonte: CGEE (2011). 
componentes destinados ao segmento de telecomunicaçóes (celulares), que registrou aumento da relação importação/faturamento de $15 \%$ para $55 \%$, nesse período. Porém, houve discreta agregação de valor em etapas de design, desenvolvimento de software e concepção, com aumento de realização no país de, respectivamente, 17,9\%, 16,3\% e 12,6\%, entre 1998 e 2008 (Tabela 4). Também se observa nesta Tabela que as empresas médias se destacaram, com maiores aumentos em todas as etapas da cadeia de valor.

TABELA 4

Variação percentual do valor adicionado pelas empresas beneficiárias, por porte, segundo etapas da cadeia de valor dos produtos incentivados

Brasil - 1998-2008

\begin{tabular}{l|c|c|c}
\hline \multicolumn{1}{c}{ Etapas da cadeia de valor } & $\begin{array}{c}\text { Pequena/ } \\
\text { Micro }\end{array}$ & Média & $\begin{array}{c}\text { Grande/Média- } \\
\text { grande }\end{array}$ \\
\hline Cadeia de suprimentos & 2.2 & 10.1 & 6.5 \\
Concepção & 3.3 & 12.6 & 10.0 \\
Desenvolvimento de hardware & 5.3 & 11.1 & 10.9 \\
Desenvolvimento de software & 5.5 & 8.6 & 16.3 \\
Design & 4.4 & 17.9 & 13.8 \\
Testes de protótipo & 1.6 & 11.3 & 8.5 \\
\hline
\end{tabular}

Fonte: CGEE (2011).

\subsection{P\&D, recursos humanos e inovação das Instituiç̧ões de Ciência e Tecnologia (ICTs)}

Os recursos aplicados em P\&D nas ICTs foram crescentes no período 1998-2008. Uma das possíveis explicações para este cenário está relacionada com o fortalecimento de algumas instituições que, como resultado desse processo, ampliaram os valores e a dimensão dos contratos para a prestação de serviços. Em alguns casos, percebe-se ainda uma diversificação dos segmentos de negócios em que as ICTs passaram a atuar, o que pode ter permitido um aumento das margens percebidas por essas instituições, como é possível observar nos Gráficos 7 a 9 que tratam especificamente do tipo de atividade realizada pelo universo de instituições respondentes.

Grande parte das ICTs da amostra iniciou o usufruto dos recursos da Lei de Informática entre 2000 e 2001. Em um primeiro momento, os recursos pro- 
venientes de convênios da Lei estiveram em patamar inferior aos recursos totais destas instituiçôes. Isso demonstra que, apesar de algumas instituiçôes terem sido criadas em função da Lei de Informática para percepção de recursos das empresas beneficiárias, as ICTs procuraram estabelecer alguma autonomia frente a essas empresas.

Observam-se, ainda, um período de distanciamento maior entre as curvas e, portanto, uma redução da participação de tais companhias no faturamento de algumas ICTs, o que denota a expansão da carteira de clientes dessas instituiçōes, possivelmente como resultado do fortalecimento dessas instituições e da diversificação do leque de serviços prestados. O descolamento das curvas (Gráfico 7), pode se dever, ainda, à alavancagem de competências nas empresas que passaram a ter uma percepção ampliada das possibilidades de investimento para um aumento da competitividade, o que teria contribuído para aumentar os investimentos internos em $\mathrm{P} \& \mathrm{D}$ em proporção maior do que os investimentos externos.

\section{GRÁFICO 7}

Investimento em P\&D nas ICTs conveniadas - recursos provenientes de convênios da Lei de Informática e recursos totais investidos

Brasil - 1998-2008

Recursos para P\&D provenientes de convênios da Lei de Informática

Recursos totais para P\&D

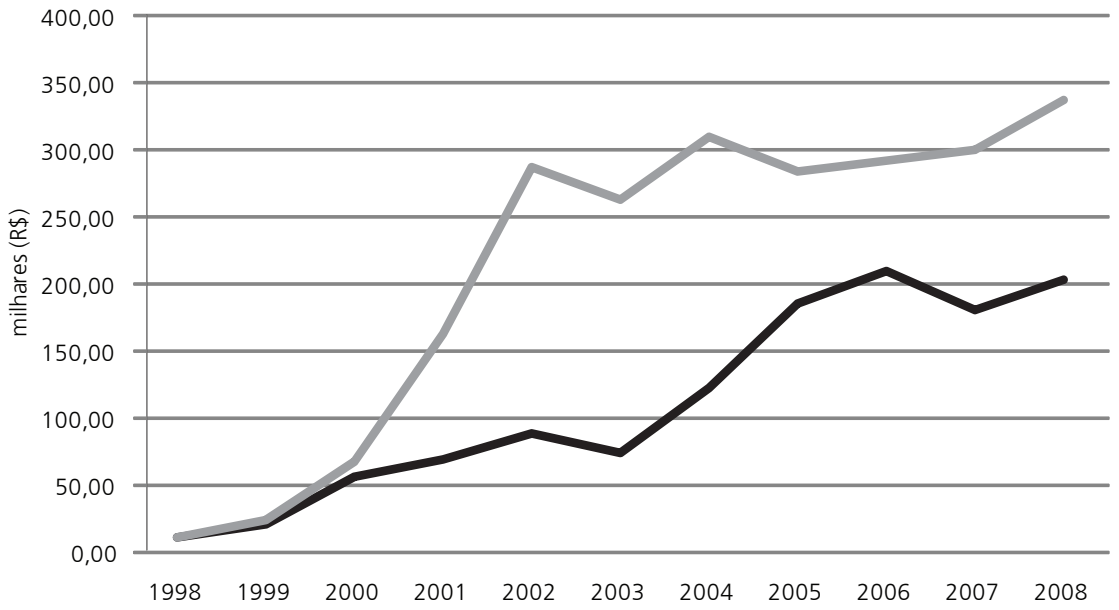

Fonte: CGEE (2011). 
Atualmente, existem 263 ICTs cadastradas no Comitê da Área de Tecnologia da Informação (Cati) e que são potenciais receptoras dos investimentos, mas apenas 92 foram citadas como tendo tido algum convênio com as empresas beneficiárias. Destas 92 instituições, 20 obtiveram $84 \%$ dos valores destinados pelas empresas no período da avaliação, o que demonstra a forte concentração dos convênios em poucas instituições.

As ICTs foram divididas, neste trabalho, em quatro categorias: privadas de ensino e pesquisa; privadas de pesquisa e desenvolvimento; públicas de ensino e pesquisa; e públicas de pesquisa e desenvolvimento. Os dados da pesquisa mostraram que, entre 1998 e 2008, das 15 ICTs com maiores valores de convênio, 74\% (11) são instituições privadas de pesquisa. Deve-se mencionar que o total de recursos aplicados, nesse período, pelas empresas nos convênios com as instituições de ciência e tecnologia privadas de pesquisa (ICTs-PP) foi de R 182 mil (83\% do total).

Nos Gráficos 8 e 9, observa-se que as ICTs-PP apresentaram um crescimento bastante acentuado a partir de 2003, principalmente como resultado de iniciativas de algumas empresas multinacionais, que criaram seus próprios institutos de pesquisa para otimizar a aplicação dos investimentos em P\&D. Em 2008, essas instituições contabilizavam quase 20 vezes mais recursos do que as ICTs públicas de ensino e privadas de ensino.

\section{GRÁFICO 8}

Investimento em P\&D com recursos da Lei da Informática, segundo perfil da ICT Brasil - 1998-2008

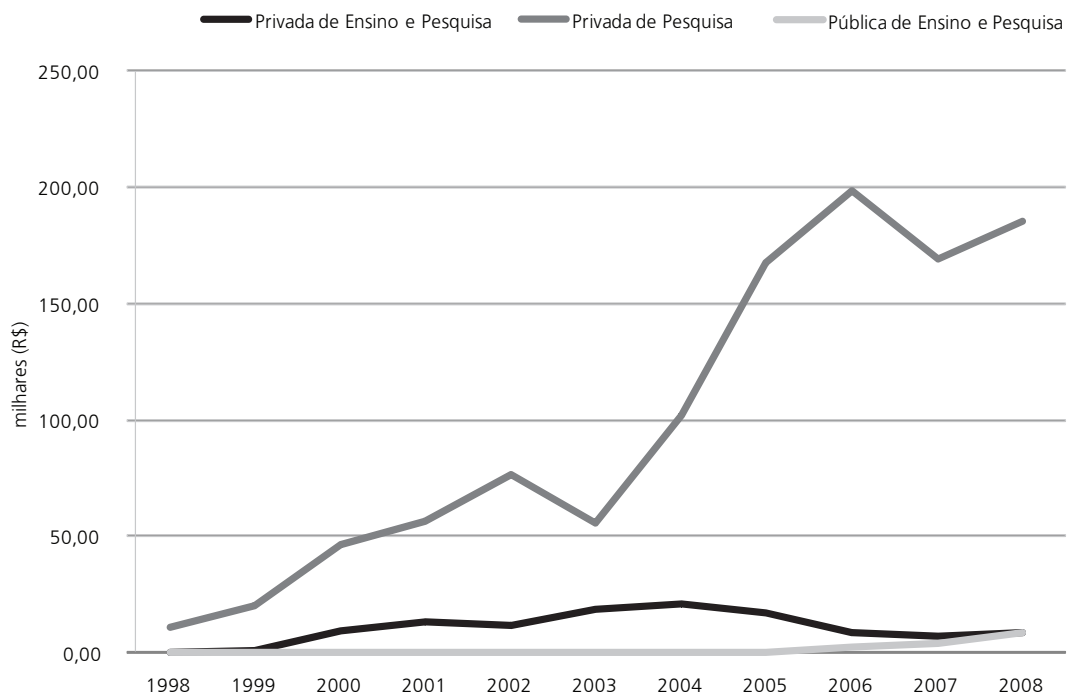

Fonte: CGEE (2011). 


\section{GRÁFICO 9}

Investimento em P\&D total, segundo perfil da ICT

Brasil, 1998-2008

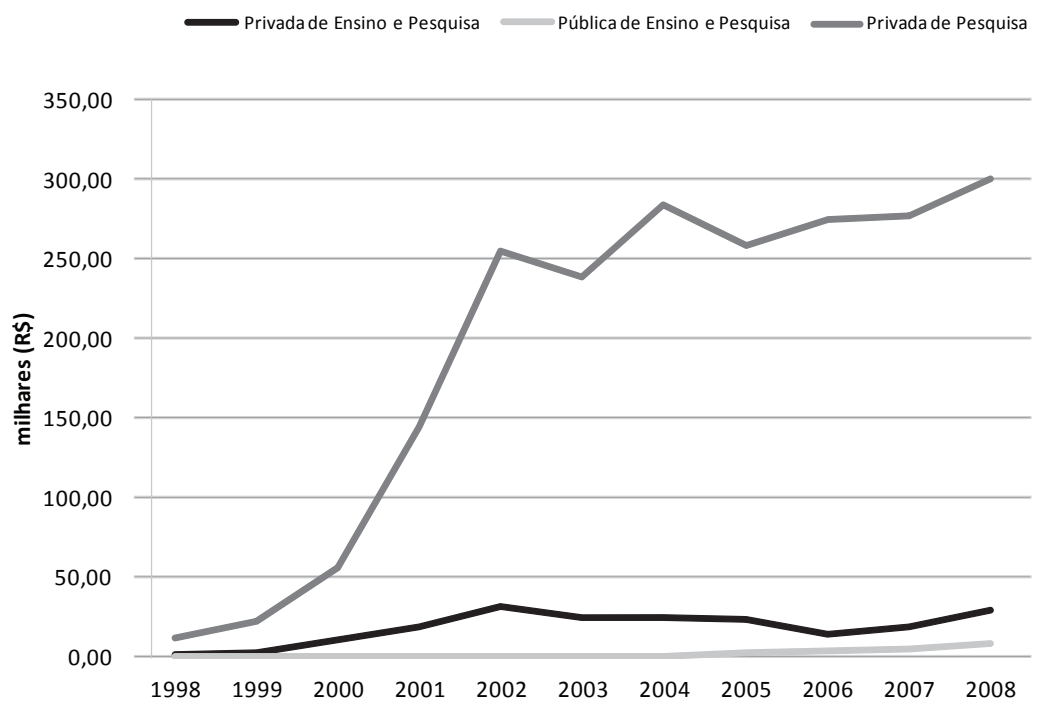

Fonte: CGEE (2011).

Os dados mostraram, ainda, que $80 \%$ dos recursos humanos das ICTs-PP estavam alocados na área de P\&D em 2008 (2.804 profissionais), com aumento de 46\%, entre 1998 e 2008. Com relação à qualificação, os profissionais com nível superior na área de P\&D passaram de 903 para 2.414, neste período, o que corresponde a um crescimento de $267 \%$, superior ao aumento de recursos humanos de nível médio na mesma área (de 519 para 903).

Apesar da considerável participação das ICTs-PP como alvo dos investimentos das empresas beneficiárias da Lei de Informática, observaram-se resultados incipientes em termos de produção científica e tecnológica: o número de publicações foi baixo e, dos 39 resultados tecnológicos desenvolvidos, 23 foram considerados novos para o país e nove novos para a instituição. Marcas e patentes foram os instrumentos de proteção à propriedade intelectual mais utilizados pelas ICTs, porém em número muito baixo em ambos os casos - 4 e 7, respectivamente, para o período 1998 a 2008.

Pela observação da natureza dos resultados tecnológicos desenvolvidos pelas ICTs e descritos nos questionários de avaliação, pode-se perceber que as atividades de pesquisa e desenvolvimento estão mais voltadas para o desenvolvimento de produtos e de software: $36 \%$ dos resultados tecnológicos geraram desenvolvimento de software e $25 \%$, desenvolvimento de produto. 
No que se refere ao tipo de atividade desenvolvida primordialmente pela área de P\&D das ICTs, observou-se, em 2008, que, no caso das ICTs públicas de ensino e pesquisa, $47,3 \%$ dos recursos foram investidos em pesquisa aplicada; para as ICTs privadas de ensino e pesquisa este percentual é de $80 \%$.

\subsection{ICTs e Desconcentração Regional}

Quanto à distribuição regional das instituições, o Gráfico 10 demonstra um relativo equilíbrio no crescimento dos investimentos em P\&D (recursos da Lei) nas Regiōes Sudeste e Nordeste/Centro-Oeste, enquanto o Sul apresentou número menor de convênios. Das 15 ICTs com maiores valores de convênios, 47\% são do Sudeste, $40 \%$ do Nordeste/Centro-Oeste e 13\% do Sul. Já no que diz respeito aos valores conveniados, entre 1998 e 2008, o Sudeste concentrou 52\% do valor total (R\$ $116 \mathrm{mi})$, enquanto as Regiōes Nordeste/Centro-Oeste receberam cerca de 40\% dos recursos investidos pelas empresas ( $\mathrm{R} \$ 85 \mathrm{mi}$ ) e o Sul ficou com apenas 13\% dos (R\$ $20 \mathrm{mi})$.

\section{GRÁFICO 10}

Investimento em P\&D oriundos de recursos da Lei da Informática Brasil - 1998-2008

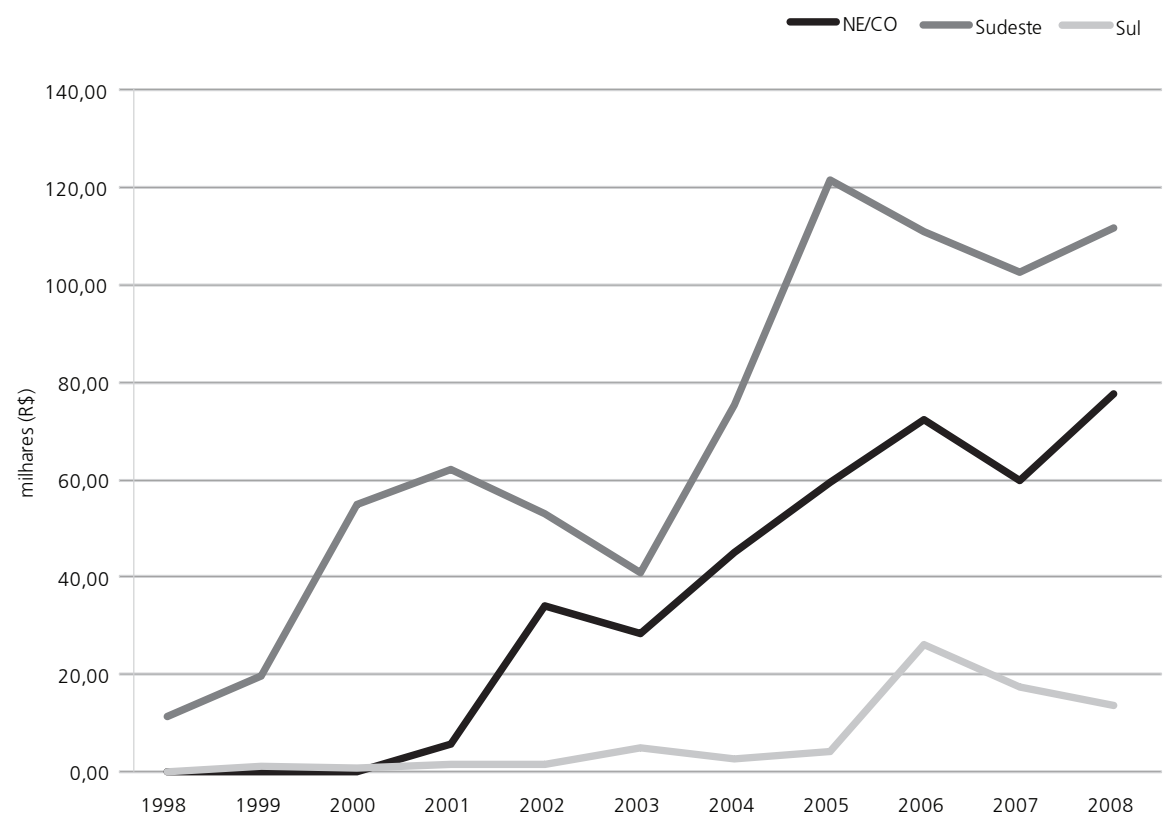

Fonte: CGEE (2011). 
Cabe destacar, ainda, que na Região Sudeste aproximadamente dois terços do total de recursos humanos empregados nas ICTs estavam alocados na área de pesquisa e desenvolvimento.

Quanto à qualificação dos recursos humanos empregados pelas ICTs das Regiōes Nordeste/Centro-Oeste, observou-se que, entre 1998 e 2008, o número de profissionais de nível superior na área de $\mathrm{P} \& \mathrm{D}$ das instituições aumentou em sete vezes (de 102 para 675), o que demonstra uma variação significativa principalmente quando comparada ao mesmo indicador no Sudeste, onde o número apenas dobrou (de 869 para 1.859). Porém, observa-se que a base de profissionais nas Regiōes Nordeste/Centro-Oeste era pequena e o crescimento do volume de recursos, como comentado, foi acentuado.

\section{Conclusões e propostas de melhorias}

No período de 1998 a 2008, a Lei de Informática promoveu aumento da produção e comercialização de bens de TICs no Brasil, porém, este crescimento foi direcionado para o mercado interno. Não houve mudança significativa da participação do país no mercado externo. Entretanto, também não ocorreu decréscimo de sua participação, como foi observado em outros players como os EUA, por exemplo.

Houve ampliação do número de empresas usuárias dos benefícios da Lei, sendo que nos anos recentes destaca-se o crescimento das pequenas e médias empresas como usuárias, o que pode denotar um processo de aprendizagem do uso dos mecanismos e mesmo um aumento da percepção da criticidade da inovação para a competitividade no setor. As empresas beneficiárias quadriplicaram seu faturamento e triplicaram sua força de trabalho e este incremento está acima da média das empresas do setor, porém, os incentivos da Lei de Informática não têm sido suficientes para conduzir o país a um lugar mais significativo no mercado global de equipamentos de TICs.

Entretanto, a Lei de Informática foi fundamental para viabilizar a fabricação de produtos de TICs incentivados no país, que, por sua vez, tiveram uma contribuição crescente no faturamento total das empresas. Houve, portanto, adensamento da cadeia produtiva de TICs no Brasil. no período estudado, mas o mesmo não se observa no aumento da densidade tecnológica do setor.

A Lei estimulou a expansão das atividades de P\&D no país, levando as empresas beneficiárias a apresentarem uma média de investimento em $\mathrm{P} \& \mathrm{D}$ três vezes maior do que a média da indústria brasileira de TICs. Porém, apesar do aumento observado nos anos recentes, especialmente a partir de 2006, este investimento se 
deu em patamares inferiores ao início dos anos 2000, como decorrência da mudança da base de cálculo dos incentivos mencionada anteriormente. Adicionalmente, este investimento foi fortemente direcionado para o desenvolvimento de produtos, em que o desenvolvimento de software embarcado em equipamentos ganha destaque: aproximadamente $60 \%$ das atividades de P\&D foram promovidas com este fim.

Este padrão de investimento refletiu-se em outros indicadores nas empresas beneficiárias, como a qualificação de recursos humanos, a geração de patentes, a produção de pesquisa e o perfil de laboratórios de P\&D de multinacionais implantados no Brasil. A proporção de pós-graduandos no total de pessoal alocado em $\mathrm{P} \& \mathrm{D}$ caiu pela metade e a de RH de nível superior manteve-se constante.

A ocorrência de publicação é muito pequena e está concentrada em poucas empresas. O número de patentes e o uso de outros instrumentos de Direito de Propriedade tiveram aumentos relativos significativos, mas em números absolutos a utilização desses instrumentos ainda é baixa.

No período de 1998 a 2008, ocorreu ampliação da participação de laboratórios de desenvolvimento de empresas multinacionais no total de laboratórios existentes: de 33\% para 67\%; porém, esse fenômeno foi acompanhado por uma mudança no perfil dos investimentos das empresas estrangeiras, direcionados majoritariamente para o desenvolvimento experimental e não para a pesquisa. Este padrão de investimento refletiu-se ainda no desenvolvimento de competências que estão fortemente focadas em adequações às necessidades do mercado e pouco relacionadas à pesquisa aplicada.

Apesar de a maioria das empresas ter relatado a ocorrência de inovações, parte das quais consideradas novas para o mundo, observa-se que boa parte delas está mais focada no desenvolvimento de produtos do que na abertura de novos nichos. Ou seja, a Lei de Informática proporcionou aumento da capacidade de inovação, porém com densidade científica e tecnológica relativamente baixa. Nas inovaçōes em âmbito mundial, destacaram-se aquelas realizadas por médias empresas em nichos especializados e pelos laboratórios de P\&D de multinacionais.

Os mecanismos da Lei de Informática estimularam mais a produção local de bens finais e menos o desenvolvimento e fabricação de insumos críticos, com efeitos limitados na agregação de valor. $\mathrm{O}$ desenho destes mecanismos privilegiou as etapas de fabricação do produto final, porém, ao longo dos anos, a agregação de valor deslocou-se das atividades relacionadas à montagem, fabricação e produção para aquelas associadas ao projeto, concepção e design dos produtos. Cabe ressaltar que, em muitos casos, uma parcela significativa do valor dos bens eletrônicos 
está associada aos componentes eletrônicos e softwares embarcados, nos quais os instrumentos da Lei de Informática não estão diretamente focalizados. Por estarem focados nas etapas de fabricação dos produtos finais, os instrumentos da Lei não estimularam, portanto, a realização de outras etapas da cadeia de valor, tais como concepção, design e testes dos produtos, ou mesmo o desenvolvimento e fabricação de componentes. Com isso, não se promoveu a entrada das empresas no fornecimento de serviços e em segmentos de hardware de maior valor agregado. A Lei viabiliza a atividade produtiva no país, mas é insuficiente para o desenvolvimento tecnológico e para ampliar a agregação de valor. Um dos aspectos que espelham esta limitada agregação de valor é o aumento da importação de insumos de alto valor diante do faturamento com produtos incentivados.

Quanto à descentralização da produção industrial, percebeu-se pouco impacto da Lei para a desconcentração regional. As Regiōes Nordeste e Centro-Oeste apresentaram impactos limitados na ampliação de sua capacidade produtiva. As principais empresas beneficiárias responsáveis pelo crescimento do faturamento total estão localizadas no Sul e Sudeste. As Regiões NE/CO respondem por um pequeno número de empresas beneficiárias do total, sendo que seu faturamento com produtos incentivados em relação ao seu faturamento total caiu durante o período. O crescimento do número de beneficiárias no NE/CO foi pequeno no período de 1998 a 2008. São empresas com foco em montagem de equipamentos, com menor esforço de P\&D, baixa proporção de RH de nível superior no total de pessoal ocupado e sem ocorrência de publicações. Nestas regiôes, os investimentos que se situam acima da obrigação legal também são menores (relação aplicaçôes/obrigações próxima de $1,0)$, notando-se, porém, que nos anos recentes vêm ocorrendo sinais de aumento dos investimentos em $\mathrm{P} \& \mathrm{D}$.

As médias empresas de capital nacional apresentaram resultados significativos em um conjunto de indicadores de impactos decorrentes da Lei de Informática. O investimento em $P \& D$ que vai além das obrigaçôes legais, nas empresas médias, variou de 1,75 a 2 vezes o valor investido na forma de contrapartida obrigatória, apresentando 50\% das inovaçóes como novidade para o país. As médias empresas também se destacam na adição de valor nas etapas da cadeia produtiva, com os maiores aumentos relativos na realização local das etapas de design, concepção, testes de protótipos, cadeia de suprimentos e desenvolvimento de hardware. Ou seja, as médias empresas estão acompanhando os esforços de $\mathrm{P} \& \mathrm{D}$ das grandes beneficiárias e, em alguns casos, registram resultados mais significativos. Parte disto acontece pela necessidade de as empresas inovarem para permanecer e crescer nos mercados. 
Note-se ainda que o recente aumento do número de médias empresas demonstra que a Lei passou a ser utilizada como instrumento efetivo para sua competitividade.

Quanto aos impactos por segmentos da indústria de TICs, observou-se que todos os segmentos apresentaram relativo desenvolvimento, mas os setores de telecomunicações e de automação industrial tiveram maiores destaques. Foi no segmento de telecomunicações-outros (excluindo celulares) que houve, em média, o dobro do investimento em P\&D, além da obrigação. Em automação industrial, este tipo de investimento, em média, foi 1,6 vez superior às obrigações. O segmento de telecomunicações-celulares apresentou a maior proporção de RH de nível superior em relação ao total de pessoal ocupado, no período de 1998 a 2008. Quanto às publicações, os segmentos que mais contribuíram foram telecomunicações $(10 \%$ do total) e automação industrial $(7,5 \%$ do total). Da mesma forma, foram estes os setores que mais inovaram.

Em relação aos impactos da Lei de Informática nas ICTs, observou-se que, ao longo dos anos, houve uma concentração do investimento em P\&D em um conjunto pequeno de ICTs (20 instituições receberam 84\% do total de investimentos), formado basicamente por ICTs-PP. Estas apresentaram crescimento bastante acentuado a partir de 2003, principalmente como resultado de iniciativas de algumas empresas multinacionais que criaram seus próprios institutos de pesquisa para otimizar a aplicação dos investimentos em P\&D. Em 2008, essas instituições contabilizavam quase 20 vezes mais recursos do que as ICTs públicas de ensino e privadas de ensino. Porém, os esforços de P\&D das ICTs-PP seguiram o mesmo padrão que as empresas beneficiárias, ou seja o foco esteve nas atividades de desenvolvimento, com resultados incipientes em termos de produção científico-tecnológica.

Quanto à desconcentração regional, os impactos da Lei nas ICTs apresentaram-se distintos daqueles observados nas empresas beneficiárias. Ou seja, devido à obrigatoriedade de parte dos investimentos ser direcionada às Regiōes Nordeste e Centro-Oeste, houve relativo equilíbrio no crescimento do investimento nestas regiōes em comparação ao Sudeste e Sul. Assim, verificou-se que os investimentos em P\&D no Nordeste/Centro-Oeste aumentaram 2,75 vezes no período 1998 a 2008. Em 2008, os investimentos nestas regiōes decorrentes dos convênios da Lei foram equivaleram a $70 \%$ do total investido no Sudeste, no mesmo ano.

A partir dos resultados observados, conclui-se que a manutenção dos mecanismos da Lei de Informática no formato em que se encontram não trará, no futuro, impactos muito diferentes daqueles mostrados no presente trabalho. A ampliação da base produtiva deu-se em proporção muito maior que a da base de criação de 
valor na indústria. É bem verdade que a Lei teve efeitos positivos sobre produção e capacitação, elevando os patamares de faturamento e de investimento em produção e em desenvolvimentos das empresas usuárias do benefício em relação às não usuárias. Entretanto, há fortes indícios de que o presente instrumento de incentivos requeira medidas adicionais para viabilizar a expansão de seus resultados e impactos, além dos patamares já atingidos

Mais ainda, há risco de que as vantagens adquiridas ao longo dos anos diminuam ou sejam perdidas em um espaço de tempo relativamente curto, dado que o incentivo de redução do IPI é limitado na sua capacidade de promover competitividade sustentada das empresas nacionais e mesmo das filiais de multinacionais aqui instaladas.

Há necessidade de novos instrumentos, complementares aos atuais, e que realmente estimulem a densidade tecnológica e a capacidade de inovação e de competição em âmbito global. A competitividade baseada apenas em custos (que já não é decisiva no caso brasileiro) e focada no mercado interno tende a agregar e apropriar muito menos valor do que aquela baseada em estímulos de competição global.

Assim, podem-se destacar alguns fundamentos para ampliação dos impactos da Lei de Informática.

- Aproveitamento dos setores competitivos - Alguns setores da indústria brasileira que têm significativa inserção internacional são grandes demandantes de produtos e serviços de TICs: petróleo e petroquímica, aeronáutica, automobilístico, mineração, agronegócio, serviços de telecomunicações, por exemplo. A indústria brasileira de TICs deve conhecer em maior profundidade as especificidades das demandas de empresas desses setores, de modo a aproveitar eventuais oportunidades para inserção no mercado internacional.

- Seletividade para inserção global - Além dos mecanismos de alcance horizontal, propõe-se que a política de informática brasileira possua instrumentos específicos de incentivo ao investimento em P\&D em segmentos ou áreas selecionadas e consideradas estratégicas, que contribuam para uma nova inserção do Brasil no mercado internacional de TICs

- Foco no mercado global e exportações - O mercado interno brasileiro é insuficiente para atender à demanda de produção em larga escala necessária a uma grande parte das empresas fabricantes de bens de TICs. Ademais, o foco no mercado externo tem a capacidade de estimular, simultaneamente, 
ganhos de escala, redução de custos e eficiência operacional e investimentos em P\&D e inovaçôes de produto e serviços de maior densidade.

- Estímulos progressivos por densidade do investimento e por resultados alcançados - Propõe-se, aqui, que aos mecanismos já existentes sejam acrescentados outros que permitam fortalecer empresas bem-sucedidas em termos dos resultados tecnológicos alcançados, assim como segmentos de alta dinamicidade na produção de inovações e com potencialidade de crescimento. Novamente, os incentivos podem ser diferenciados em função da densidade do investimento em tecnologia e inovação e em função dos resultados e impactos alcançados.

- Critérios para identificação de empresas/segmentos de alta dinamicidade em TICs - Estratégia tecnológica coerente e arrojada; ênfase na inserção global; cultura de inovação; agregação de valor nas cadeias locais; participação no mercado internacional; qualificação da mão de obra; densidade das atividades de P\&D; resultados passados.

- Monitoramento - Deve-se considerar que o constante acompanhamento e a avaliação dos impactos obtidos das atividades desenvolvidas são fundamentais para que governo e empresas reavaliem suas estratégias e promovam esforços substanciais que estruturem efetivamente uma cultura de pesquisa e desenvolvimento no país. Adicionalmente, sugere-se uma revisão periódica do leque de atividades consideradas elegíveis como pesquisa e desenvolvimento para percepção dos recursos destinados a este fim, no intuito de que a política brasileira acompanhe e contemple, no âmbito de seus mecanismos, as mudanças no contexto global da dinâmica de inovação do setor.

\section{Referências bibliográficas}

BRASIL. Ministério da Ciência e Tecnologia. Tecnologia da Informação - Legislação brasileira. Brasília: MCT, 2009.

CGEE. Avaliação de impactos da Lei de Informática no Brasil - 1998 a 2008. Brasil.2011. Disponível em: <http://www.ige.unicamp.br/geopi/publicacoes.php?sub=outros>.

IBGE. Pesquisa Industrial Anual - PIA 2007 - Empresas. Rio de Janeiro: IBGE, 2007. Pesquisa Industrial de Inovação Tecnológica - Pintec 2008. Rio de Janeiro: IBGE, 2010. 
. Pesquisa Industrial de Inovação Tecnológica - Pintec 2000. Rio de Janeiro: IBGE, 2002. . Pesquisa Industrial de Inovação Tecnológica - Pintec 2003. Rio de Janeiro: IBGE, 2005. . Pesquisa Industrial de Inovação Tecnológica - Pintec 2005. Rio de Janeiro: IBGE, 2008.

OCDE. Towards a knowledge-based economy. Paris: OECD Science, Technology and Industry Scoreboard, Organisation for Economic Co-operation and Development -: OECD, 2001. Working party on indicators for the information society - Guide to measure the information society. Paris: OECD, 2005.

. OECD information technology outlook: information and communications technologies. Paris: Directorate for Science Technology and Industry, OECD, 2006. . OECD information technology outlook. Paris: Directorate for Science Technology and Industry, OECD, 2008.

SALLES-FILHO, S.; BONACELLI, M. B.; CARNEIRO, A. M.; DE CASTRO, P. D.; SANTOS, F. O. Evaluation of ST\&I programs: a methodological approach to the Brazilian Small Business Program and some comparisons with the SBIR program. Research Evaluation, v. 20, p. 157-169, 2011.

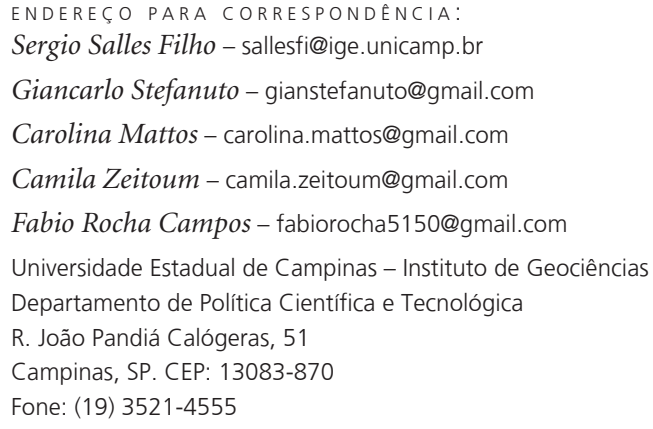

